\title{
Disputes Using Machine Learning Techniques Classifying Compensations in Construction
}

\author{
Murat Ayhan*, Irem Dikmen** and M. Talat Birgonul** \\ *Department of Civil Engineering, Gazi University, Ankara, 06570, Turkey. \\ **Department of Civil Engineering, Middle East Technical University, Ankara, 06800, Turkey. \\ *Email: muratayhan@gazi.edu.tr; Corresponding Author.
}

Submitted: $10-10-2020$

Revised: 11-09-2021

Accepted: 20-09-2021

\begin{abstract}
It is highly probable to encounter disputes in construction projects and construction disputes are detrimental as they may lead to cost overruns and delays. Knowing the compensation with some certainty can avoid parties from extending inconclusive claims. Decision support systems can be helpful to understand the aspect of the compensation, if any compensation can be acquired. Within this context, the primary objective of this research is to predict the associated compensations in construction disputes by using machine learning (ML) techniques on past project data so that in new projects, decision support can be provided with some certainty via forecasts on the aspect of the compensation. To do this, a conceptual model identifying the attributes affecting compensations was established based on an extensive literature review. Using these attributes, data from real-world dispute cases were collected. Insignificant attributes were eliminated via Chi-square tests to establish a simpler classification model, which was experimented via alternative single and ensemble ML techniques. The Naïve Bayes (NB) classifier generated the highest average classification accuracy as $80.61 \%$ when One-vs-All (OvA) decomposition technique was utilized. The conceptual model can guide construction professionals during dispute management decisionmaking and the promising results indicate that the classification model has the potential to identify compensations. This study can be used to mitigate disputes by preventing parties from resorting to unpleasant and inconclusive resolution processes.
\end{abstract}

Keywords: Construction disputes; Compensation; Machine learning; Data classification; Dispute management.

\section{INTRODUCTION}

Construction industry is exceptionally susceptible to conflicts and disputes that often lead to lawsuits (Awwad et al., 2016), and it has a notoriety for being contentious (Arditi and Pulket, 2005). Time and cost are the main determinants of success in a construction project. However, disputes have the potential to disrupt the workflow and lead to cost overruns and delayed schedules (Kisi et al., 2020). Therefore, dispute management is of vital importance in achieving successful projects. On the other hand, dispute management is a challenging decisionmaking problem because of its dependence to numerous complex and interrelated factors (Chou, 2012). Moreover, construction disputes are already complex technically and legally in nature.

Specifically, claims are frequently observed in construction industry, and they generally lead to delays. Delays can result in extension of time (EOT), liquidated damages, or monetary compensation. At the same time, cost overrun is also a frequently observed phenomenon that is caused by disagreements between the parties, and there is no applicable model for measuring the contribution of claims on cost overrun (Sharifi and Bagherpour, 2016). As a result, professionals struggle to analyze possible gains and losses in a dispute (Ilter, 2010), and the task of identifying the relationship between time and cost is particularly difficult considering the variety of activities in construction projects.

Despite the mentioned complexities, the dispute management decision-making in construction industry is rather subjective and intuitive that is based on the experience and knowledge of the decision-maker (Chou et al., 2013). However, the need for a more systematic approach is evident (Ilter, 2010). Artificial Intelligence (AI) domain offers several systematical solutions to mitigate the subjectivity, which is dominant in dispute management decisionmaking (Cheung et al., 2004). Specifically, machine learning (ML) techniques allow to develop systems capable 
of learning from past data about a specific task automatically, while simulating the underlying relationships between numerous input and output variables that are difficult to rationalize; as a result, target labels (i.e., compensations) can be predicted based on prespecified features (Siam et al., 2019). This paper argues that knowing the potential compensation with some certainty can avoid parties from extending their claims. Parties may benefit from decision support systems that help them to understand whether they can acquire any compensation and in what aspect depending on the disputed case characteristics. Within this context, it is hypothesized that compensations in construction disputes can be forecasted by using ML techniques. To this end, the objectives of this research are (1) to propose a novel conceptual model that identifies the factors affecting compensations in construction disputes, and (2) to propose an empirical ML-based classification model that can support the decisionmaking process. The conceptual model depends on findings of an extensive literature review, and it is expected to act as an effective guide for professionals during decision-making by highlighting the influential factors related to compensations. Meanwhile, the classification model can provide early-warning to identify compensations so that parties can prefer not to extend their claims, and with this better understanding about their claims, they can avoid inconclusive resolution processes.

\section{RESEARCH BACKGROUND}

The negative impacts of disputes on construction projects are well understood and documented; however, the industry is still searching methods for avoidance or mitigation as increasing numbers of disputes are being reported (Awwad et al., 2016). The appropriate approach against disputes is seeking for their avoidance and avoiding actions can only be taken by prediction (Fenn, 2007). Consequently, many prediction studies can be found in the related literature. Chou et al. (2014) have investigated the performances of several ML techniques to predict dispute occurrence. Arditi and Pulket (2005 \& 2010) predicted the outcomes of construction litigation via AI techniques. Similarly, Chen and Hsu (2007) developed a classification model that predicts the litigation probability of a project, and Chau's (2007) model predicted the outcomes of claims if the cases were taken to courts. Chou (2012) and Chou et al. (2013) developed ML-based models to forecast the appropriate dispute resolutions.

Despite the above-mentioned efforts, the industry is still overwhelmed by increasing number and severity of disputes. Therefore, this research proposed development of an ML-based model to forecast compensations prior to resolution processes. Although ML techniques were used to predict dispute types and stages that achieved $79.77 \%$ and $77.00 \%$ average 10 -fold cross-validation (CV) accuracies, respectively (Chou et al., 2016), there are no applicable models to forecast compensations. Moreover, the literature mainly focuses on quantification of claims and disputes. These efforts include delay analysis and claim preparation efforts. For example, Nasirzadeh et al. (2019) developed an approach to quantify the impacts of claims. However, there are counter opinions stating that it is not possible to quantify claims precisely even with the best information available (Ren et al., 2001). Thus, prior to quantification of claims, this research intends to identify (1) acquisition of any compensation, and (2) aspect of the compensation (i.e., time, cost, or both).

\section{RESEARCH METHODOLOGY}

This research has three main steps as presented in Figure 1. The first step involves developing a conceptual model based on literature review, and 31 frequently perceived attributes were identified for the conceptual model. These attributes were grouped in five categories as (1) project characteristics (i.e., project location), (2) characteristics/organizational structures of the parties involved (i.e., communication between parties), (3) occurrence of changes or unexpected events, (4) delays, and (5) dispute characteristics (i.e., disputed amount). The details related to determination of 31 attributes can be found in Ayhan (2019), which proposed three conceptual models to depict the common factors affecting dispute occurrence, compensations, and resolution method selection that led to development of three distinct classification models. The first model was developed to distinguish disputed and undisputed projects. The second model, which is the subject of this paper, classified compensations. Finally, the third model was for determining the appropriate resolution method. 


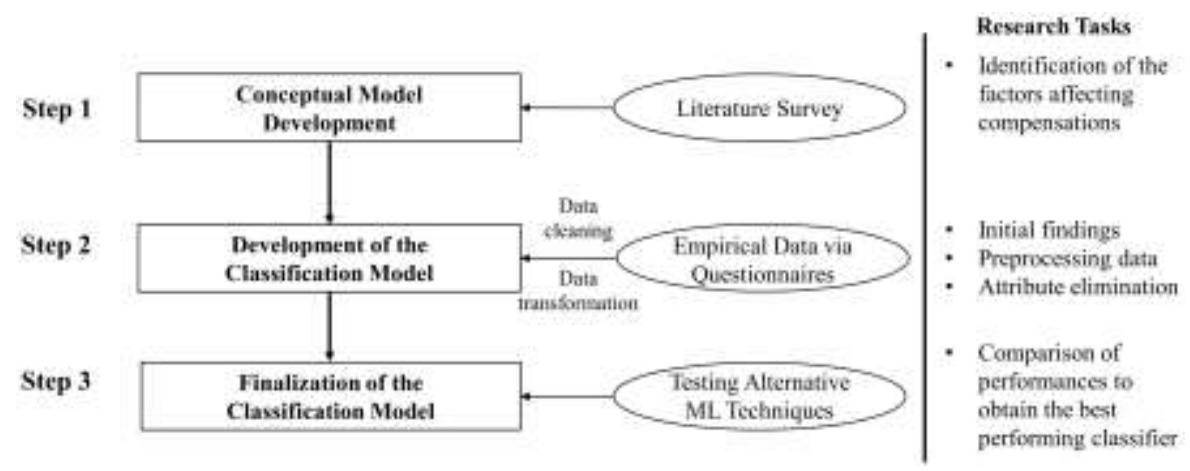

Figure 1. Research methodology

The second step involves development of classification model that is based on empirical data from past projects. A questionnaire was designed to collect data related to all attributes in the conceptual model. The dataset was cleaned from noise and preprocessed for computational purposes. Then, Chi-square tests were conducted for attribute elimination that generated the final model. IBM SPSS Statistics version 22.0 was used for Chi-square tests. The third step is the finalization of the model that involves comparison of performances of alternative ML techniques. WEKA version 3.8.3 (Frank et al., 2016) was used in experiments. The classifier that generates the highest accuracy becomes the final model for classification of compensations.

\section{DATA COLLECTION AND PREPARATION}

The questionnaires were conducted via face-to-face and online meetings with 78 participants. The opinions from senior professionals were obtained in this study as the average experience of the participants in the construction industry was 18 years, where $47.0 \%$ possessed more than 15 years of experience. The participants returned data about 151 construction projects; however, after removal of noisy and unrepresentative data, the dataset contained 108 instances among which were 38 undisputed projects $(35.2 \%)$. The 70 disputed projects $(64.8 \%)$ encountered 82 distinct dispute cases that were used in classification tasks.

In this research, attributes with numeric data types were converted to categorical variables due to computational requirements of the utilized techniques. For example, Chi-square statistic which is a convenient method of identifying the associations among categorical attributes (Weisburd and Britt, 2007), is utilized in this research for attribute elimination. Therefore, all attributes should be discretized. Moreover, the Naïve Bayes (NB) algorithm can only work with discrete data. In order to compare the performances of all utilized ML techniques under the same conditions, regardless of the technique's capability to handle various data types, the same discretized data set should be used in all classification experiments. However, discretization of a numeric attribute will cause loss of information at some extent, which may damage the accuracy of the classification algorithms. Therefore, the process should be handled with care as there is a risk of removing distinctive properties of an attribute. Discretization boundaries should be selected such that minimum loss of information will be experienced. For this reason, the information gain-based supervised discretization method in WEKA was utilized. This method can minimize the information loss by selecting split points that generates the largest gain. Moreover, the subjectivity during conversion can also be minimized as discretization boundaries are selected based on the output class.

\section{CHI-SQUARE TESTS AND THE CLASSIFICATION MODEL}

The presence of insignificant or irrelevant attributes may negatively impact ML algorithms and their elimination can improve the performance (Arditi and Pulket, 2010). In this study, Chi-square statistic was utilized to identify the associations between the attributes and the compensations, where statistically insignificant attributes were eliminated to obtain the final classification model. Chi-square statistic can handle input variables having multiple categories. Moreover, it is robust against the data distribution, unlike many other methods that can only operate on data with almost normal distribution (McHugh, 2013). Thus, Chi-square statistic is adequate for attribute elimination due to features of the dataset used in this study. However, it is not possible to measure the strength of association via Chi-square tests and thus, additional measures are needed. In this research, Cramer's V was preferred for measuring the strength of association for nominal variables and Somers' $\mathrm{d}$ for ordinal variables. Both measures are suitable for this dataset as they can operate on input and output variables with unequal number 
of categories (Weisburd and Britt, 2007). Test outputs are given in Table 1. The probability values (p-value) were checked at 0.05 significance level for $95 \%$ confidence interval (CI). Attributes with lower p-values than this threshold were used in the final classification model since they have statistically significant association with compensations.

Table 1. Conceptual model attributes and results of Chi-square tests

\begin{tabular}{|c|c|c|c|}
\hline ID & Attribute & p-value & $\begin{array}{l}\text { Selected for } \\
\text { Final Model }\end{array}$ \\
\hline PC1 & Project Location & 0.068 & $\mathrm{NO}$ \\
\hline PC2 & Project (Contract) Value & 0.291 & NO \\
\hline PC3 & Planned Project Duration & 0.716 & $\mathrm{NO}$ \\
\hline PC4 & Type of Construction & 0.237 & NO \\
\hline PC5 & Type of Contractor & 0.010 & YES \\
\hline PC6 & Type of Employer & 0.075 & NO \\
\hline PC7 & Type of Contract & 0.010 & YES \\
\hline PC8 & Payment Method & 0.335 & NO \\
\hline PC9 & Project Delivery System & 0.680 & NO \\
\hline PC10 & Level of Design Complexity & 0.689 & NO \\
\hline PC11 & Level of Construction Complexity & 0.275 & NO \\
\hline S1 & Relationship between Parties & 0.082 & $\mathrm{NO}$ \\
\hline S2 & Previous Experience with Each Other & 0.647 & NO \\
\hline S3 & Dispute Avoidance Incentive & 0.417 & NO \\
\hline S4 & Communication between Parties & 0.390 & NO \\
\hline S5-1 & Working Culture \& Skills of Represented Party & 0.280 & NO \\
\hline S5-2 & Working Culture \& Skills of Counter Party & 0.443 & $\mathrm{NO}$ \\
\hline S6-1 & Resp. Rate \& Communication Skills of Repr. Party & 0.193 & NO \\
\hline S6-2 & Resp. Rate \& Communication Skills of Counter Party & 0.105 & NO \\
\hline S7-1 & Experience of Represented Party & 0.061 & NO \\
\hline S7-2 & Experience of Counter Party & 0.562 & NO \\
\hline S8-1 & Project Manage. \& Coord. Skills of Represented Party & 0.160 & $\mathrm{NO}$ \\
\hline S8-2 & Project Manage. \& Coord Skills of Counter Party & 0.795 & NO \\
\hline
\end{tabular}




\begin{tabular}{|l|l|c|c|}
\hline C1 & Changes & 0.000 & YES \\
\hline D1 & Delays & 0.000 & YES \\
\hline DC1 & Disputant Party & 0.017 & YES \\
\hline DC2 & Phase of Occurrence & 0.069 & NO \\
\hline DC3 & Dispute Source & 0.000 & YES \\
\hline DC4 & Suspension of Works & 0.622 & NO \\
\hline DC5 & Disputed Amount (Financially) & 0.019 & YES \\
\hline DC6 & Disputed Extension of Time Amount & 0.000 & YES \\
\hline
\end{tabular}

For this dataset, results showed that only eight attributes were in the final model among 31 attributes of the conc eptual model (Figure 2). The contingency table of the attributes in the classification model is given in Table 2 along with the strength of association values of each attribute for better understanding related to the most influential factors.

Table 2. Contingency table and strength of association values for the selected attributes

\begin{tabular}{|c|c|c|c|c|c|c|}
\hline \multirow[b]{2}{*}{ ID } & \multirow[b]{2}{*}{ Categories } & \multicolumn{4}{|c|}{$\begin{array}{c}\text { Compensation Type } \\
\text { (Relative Frequency }(\%) \text { ) }\end{array}$} & \multirow[b]{2}{*}{$\begin{array}{l}\text { Strength of } \\
\text { Association }\end{array}$} \\
\hline & & No & $\begin{array}{l}\text { Cost } \\
\text { Only }\end{array}$ & $\begin{array}{l}\text { Time } \\
\text { Only }\end{array}$ & $\begin{array}{c}\text { \& } \\
\text { Time }\end{array}$ & \\
\hline \multirow{3}{*}{ PC5 } & Single & 18.5 & 49.2 & 4.6 & 27.7 & \multirow{3}{*}{$\begin{array}{c}\text { Cramer's V } \\
0.327\end{array}$} \\
\hline & Joint Venture & 0.0 & 54.5 & 0.0 & 45.5 & \\
\hline & Consortium & 0.0 & 0.0 & 33.3 & 66.7 & \\
\hline \multirow{4}{*}{ PC7 } & Private & 14.0 & 60.5 & 0.0 & 25.5 & \multirow{4}{*}{$\begin{array}{c}\text { Cramer's V } \\
0.297\end{array}$} \\
\hline & Public & 16.7 & 38.9 & 22.2 & 22.2 & \\
\hline & FIDIC Red & 20.0 & 20.0 & 6.7 & 53.3 & \\
\hline & FIDIC Silver / Yellow & 0.0 & 33.3 & 0.0 & 66.7 & \\
\hline \multirow{2}{*}{$\mathrm{C} 1$} & Yes & 21.1 & 25.0 & 5.8 & 48.1 & \multirow{2}{*}{$\begin{array}{c}\text { Cramer's V } \\
0.585\end{array}$} \\
\hline & No & 3.3 & 83.3 & 6.7 & 6.7 & \\
\hline \multirow{2}{*}{ D1 } & $0 \%$ & 9.5 & 90.5 & 0.0 & 0.0 & \multirow{2}{*}{$\begin{array}{c}\text { Somers' d } \\
0.294\end{array}$} \\
\hline & $0 \%-20 \%$ & 33.3 & 14.3 & 9.5 & 42.9 & \\
\hline
\end{tabular}




\begin{tabular}{|c|c|c|c|c|c|c|}
\hline & $20 \%-40 \%$ & 11.8 & 47.0 & 11.8 & 29.4 & \\
\hline & $>40 \%$ & 4.3 & 34.8 & 4.3 & 56.5 & \\
\hline \multirow{2}{*}{$\mathrm{DC} 1$} & Client & 9.1 & 90.9 & 0.0 & 0.0 & \multirow{2}{*}{$\begin{array}{c}\text { Cramer's V } \\
0.361\end{array}$} \\
\hline & Contractor & 15.5 & 39.4 & 7.0 & 38.0 & \\
\hline \multirow{10}{*}{ DC3 } & Cost of Change Orders & 42.9 & 57.1 & 0.0 & 0.0 & \multirow{10}{*}{$\begin{array}{c}\text { Cramer's V } \\
0.584\end{array}$} \\
\hline & Time \& Cost of Change Orders & 4.8 & 4.8 & 9.5 & 81.0 & \\
\hline & $\begin{array}{l}\text { Measurement \& Valuation of } \\
\text { Contracted Works }\end{array}$ & 0.0 & 100.0 & 0.0 & 0.0 & \\
\hline & Delay in Site Handover \& Possession & 0.0 & 0.0 & 0.0 & 100.0 & \\
\hline & Defects, Errors, Poor Quality & 12.5 & 75.0 & 12.5 & 0.0 & \\
\hline & $\begin{array}{l}\text { Contractor Fails to Act as a Prudent } \\
\text { Merchant }\end{array}$ & 0.0 & 75.0 & 12.5 & 12.5 & \\
\hline & Delays in Payments & 0.0 & 100.0 & 0.0 & 0.0 & \\
\hline & Substantial Changes in BoQ & 0.0 & 100.0 & 0.0 & 0.0 & \\
\hline & Inadequate Site/Soil Investigation & 37.5 & 12.5 & 0.0 & 50.0 & \\
\hline & Interpretation of Contract Clauses & 50.0 & 25.0 & 12.5 & 12.5 & \\
\hline \multirow{4}{*}{ DC5 } & $<5$ mil. $\$$ & 15.4 & 64.1 & 5.1 & 15.4 & \multirow{4}{*}{$\begin{array}{l}\text { Somers' d } \\
0.248\end{array}$} \\
\hline & $5-25$ mil. \$ & 9.1 & 36.4 & 13.6 & 40.9 & \\
\hline & $25-75$ mil. \$ & 0.0 & 44.4 & 0.0 & 55.6 & \\
\hline & $>75$ mil. $\$$ & 33.3 & 8.3 & 0.0 & 58.3 & \\
\hline \multirow{4}{*}{ DC6 } & 0 days & 19.6 & 80.4 & 0.0 & 0.0 & \multirow{4}{*}{$\begin{array}{l}\text { Somers' d } \\
0.659\end{array}$} \\
\hline & $0-0.5$ year & 0.0 & 7.7 & 15.4 & 76.9 & \\
\hline & $0.5-1$ year & 9.1 & 0.0 & 27.3 & 63.6 & \\
\hline & $>1$ year & 16.7 & 0.0 & 0.0 & 83.3 & \\
\hline
\end{tabular}

\section{ALGORITHMS}

The experimented algorithms were taken from a survey that listed the top 10 data mining algorithms (Witten et al., 2017). Among them, five algorithms can be used in classification tasks and multilayer perceptron (MLP) is also experimented due to its wide use in construction research. Thus, the algorithms in this research are (1) NB, (2) K-Nearest Neighbor (KNN), (3) C4.5, (4) MLP, (5) Polynomial Kernel Support Vector Machines (PSVM), and (6) Radial Basis. 


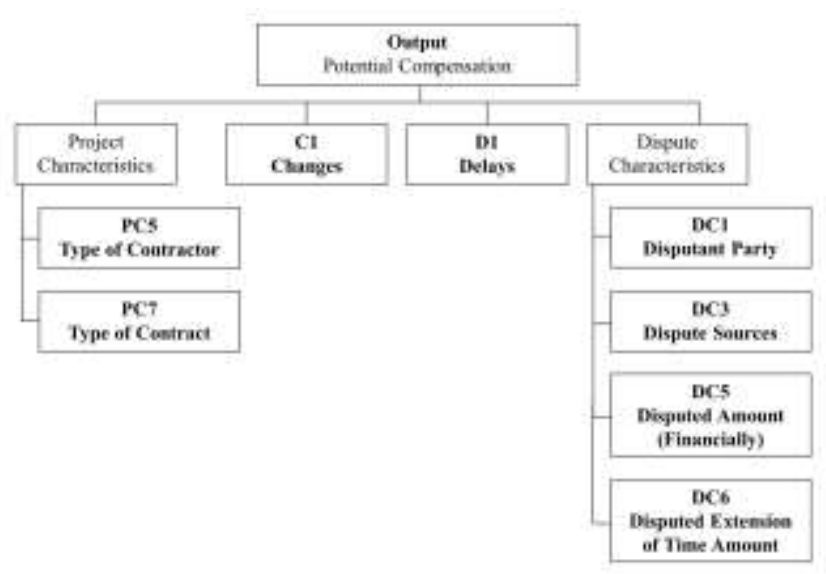

Figure 2. Attributes of the classification model

Function Kernel Support Vector Machines (RBF-SVM). In addition, three ensemble techniques were also considered for potential enhancement in classification performance, which are (1) voting, (2) stacking, and (3) AdaBoost algorithm. Voting was preferred since it is reported as the simplest way to combine single classifiers; stacking due to its potential to generate better classifier combinations; AdaBoost algorithm due to its wide use, ease of implementation, and adaptability to a wide range of classifiers (Witten et al., 2017). Theoretical explanations related to the utilized ML algorithms will exceed the scope of this paper. However, it should be noted that each technique has parameters to be optimized for obtaining the best performance. WEKA offers several methods such as $\mathrm{CV}$ parameter selection and grid search for detection of optimum parameters within prespecified search ranges.

Classification of compensations is a multiclass classification problem that can be solved naturally by extending the binary classification capabilities of the experimented algorithms. However, SVM is designed for binary problems, and it cannot handle multiclass solutions. For this reason, the multiclass problem should be decomposed into several binary classification tasks. WEKA offers four decomposition techniques as (1) One-vsOne (OvO), (2) One-vs-All (OvA), (3) Random Correction Code (RCC), and (4) Exhaustive Correction Code (ECC). Considering this, besides the multiclass solutions, the problem was also solved by using these decomposition techniques for all evaluated algorithms.

\section{DATA CLASSIFICATION RESULTS}

Due to the limited amount of data, 10-fold CV technique was utilized in this research. Moreover, in the dataset, it is observed that cost compensation was acquired in $46 \%$ of the disputes, time compensation in $6 \%$, both cost and time compensation in 33\%, and no compensation was acquired in $15 \%$ of the cases. Therefore, random sampling in CV may generate imbalanced representation. For this reason, stratified 10-fold CV technique was utilized. To decrease the variance associated with CV technique, all experiments were repeated 10 times and the results were obtained by taking the average of accuracy values from each repetition.

Table 3 shows the 10 times repeated 10-fold CV results of the single classifiers. NB and MLP algorithms generated the highest average classification accuracy when OvA decomposition technique was utilized. For KNN and $\mathrm{C} 4.5$, the best performance was obtained from the multiclass solution without decomposing the problem. Both SVM classifiers generated their best results when ECC technique was utilized. The most successful classifiers were $\mathrm{NB}, \mathrm{KNN}$, and $\mathrm{C} 4.5$ with $80.61 \%, 78.66 \%$, and $76.95 \%$ average classification accuracy, respectively. Moreover, the NB classifier outperformed others in average precision, recall, and area under receiver operating characteristic curve (AUC) measures.

Table 3. 10-times 10-fold cross-validation performance of single classifiers

\begin{tabular}{lccccc}
\hline Classifier & $\begin{array}{c}\text { Average } \\
\text { Accuracy }(\%)\end{array}$ & $\begin{array}{c}\text { \%95 CI Accuracy } \\
(\boldsymbol{\%})\end{array}$ & $\begin{array}{c}\text { Average } \\
\text { Precision }\end{array}$ & $\begin{array}{c}\text { Average } \\
\text { Recall }\end{array}$ & $\begin{array}{c}\text { Average } \\
\text { AUC }\end{array}$ \\
\hline NB OvA & 80.61 & $(80.11-81.10)$ & 0.774 & 0.806 & 0.916
\end{tabular}




$\begin{array}{lccccc}\text { KNN (Multiclass) } & 78.66 & (77.05-80.26) & 0.737 & 0.787 & 0.912 \\ \text { C4.5 (Multiclass) } & 76.95 & (75.99-77.91) & 0.632 & 0.769 & 0.811 \\ \text { MLP OvA } & 68.63 & (67.03-70.23) & 0.666 & 0.686 & 0.842 \\ \text { P-SVM ECC } & 74.39 & (72.97-75.81) & 0.660 & 0.744 & 0.825 \\ \text { RBF-SVM ECC } & 73.41 & (72.34-74.49) & 0.626 & 0.733 & 0.827\end{array}$

The best performing three classifiers were experimented further by using voting and stacking techniques to develop ensemble classifiers in pursue of an enhancement to classification performance. In voting, the classification decisions of the best performing three single algorithms were combined. In stacking, two single techniques were combined as base-learners and meta-learners such that, base-learners were selected among the top performing three single

classifiers and meta-learners were selected among the remaining five single classifiers, excluding the one used as the base-learner. Thus, 15 stacked classifiers were experimented in this research. Moreover, all single classifiers were boosted by AdaBoost algorithm. Table 4 shows the 10 times repeated 10 -fold $\mathrm{CV}$ results of the ensemble classifiers that outperformed their single counterparts.

Table 4. 10-times 10-fold cross-validation performance of ensemble classifiers

\begin{tabular}{lccccc}
\hline Classifier & $\begin{array}{c}\text { Average } \\
\text { Accuracy }(\%)\end{array}$ & $\begin{array}{c}\text { \%95 CI } \\
\text { Accuracy (\%) }\end{array}$ & $\begin{array}{c}\text { Average } \\
\text { Precision }\end{array}$ & $\begin{array}{c}\text { Average } \\
\text { Recall }\end{array}$ & $\begin{array}{c}\text { Average } \\
\text { AUC }\end{array}$ \\
\hline Majority Voting & 80.61 & $(79.57-81.65)$ & 0.755 & 0.806 & 0.850 \\
$\begin{array}{l}\text { Stacking: } \\
\text { C4.5 (Multiclass)+MLP OvA }\end{array}$ & 77.56 & $(76.95-78.17)$ & 0.617 & 0.775 & 0.803 \\
$\begin{array}{l}\text { Stacking: } \\
\text { C4.5 (Multiclass)+RBF-SVM ECC }\end{array}$ & 77.20 & $(76.37-78.02)$ & 0.618 & 0.772 & 0.810 \\
AdaBoost: MLP OvA & 71.10 & $(69.40-72.80)$ & 0.689 & 0.711 & 0.853 \\
\hline
\end{tabular}

\section{DISCUSSION OF FINDINGS}

The literature review revealed 31 attributes under five categories as impacting factors on compensations and they were used to develop a conceptual model, which can be utilized with different datasets to conduct similar research. Using the conceptual model, the dataset was collected, and Chi-square tests showed that eight attributes have significant association with compensations. Among PC attributes, the type of contractor (PC5) and contract (PC7) were selected. Considering that contract is the basis for claims and disputes, the importance of PC7 was expected. However, it was interesting to observe that if the contractor is not a single company (i.e., joint-venture or consortium), the chance of acquiring compensation is more likely. Chi- square tests revealed that none of the attributes in S category had significant influence on compensations. Thus, characteristics of the parties in a dispute were not associated with compensations. In case of changes or unexpected events $(\mathrm{C} 1)$, the disputant party acquired both cost and time compensations in majority of the cases (48.1\%). Moreover, as the ratio of delays to the planned project duration (D1) increases, the probability to acquire compensations increases. For projects with a delay ratio lower than $20 \%$, cost compensation was acquired in $57.2 \%$ of the cases and time compensation in $52.4 \%$. Meanwhile, for projects with a delay ratio higher than $40 \%$, cost compensation was acquired in $91.3 \%$ of the cases and time compensation in $60.8 \%$. Another interesting finding was related to the disputed amount (DC5) as it is more likely to acquire monetary compensation in disputes with lower cost claims. For disputes greater than 5 million USD, $64.1 \%$ of the cases ended up with cost compensation. Meanwhile, this rate was $36.4 \%$ for disputes with a value between 5 to 25 million USD, 44.4\% for cases between 25 to 75 million USD, and 8.3\% for cases 
higher than 75 million USD. A similar association was observed for disputed EoT amount (DC6) such that disputes with lower EoT claims have more probability to acquire time compensation. The strongest associations were obtained from DC6 (0.659) in terms of Somers' d measure and from C1 (0.585) and DC3 (0.584) in terms of Cramer's V. Thus, these three attributes were the most influential factors on compensations.

The NB, KNN, and C4.5 classifiers are the best performing single classifiers with average accuracies of $80.61 \%, 78.66 \%$, and $76.95 \%$, respectively. Ensemble classifiers were also developed to achieve better performance; however, none of the ensemble classifiers managed to outperform the best single classifier. The classifier obtained from majority voting achieved the same average accuracy with NB classifier (80.61\%). However, the NB OvA classifier outperformed majority voting in precision and AUC measures as can be seen in Table 5 .

Table 5. Comparison of best classifiers (single vs. ensemble)

\begin{tabular}{lcccc}
\hline & \multicolumn{4}{c}{ Average Values from 10 Repetitions } \\
\cline { 2 - 5 } Classifier & Accuracy & Precision & Recall & AUC \\
\hline NB OvA & $80.61 \%$ & 0.774 & 0.806 & 0.916 \\
Majority Voting & $80.61 \%$ & 0.755 & 0.806 & 0.850 \\
\hline
\end{tabular}

The literature is scarce in empirical studies that utilize ML techniques to forecast dispute related problems. In Chou et al. (2013), dispute resolution classification was achieved by using SVM with an average 10-fold CV accuracy of $61.75 \%$ and by integrating SVM, genetic algorithm, and fuzzy logic with $77.04 \%$ average accuracy. In Chou et al. (2016), the dispute type was predicted with an average 10-fold CV accuracy of $77.00 \%$ via C5.0 algorithm. Thus, the effort in this paper to classify compensations in construction disputes with an average accuracy of $80.61 \%$ is claimed to be a promising result.

\section{CONCLUSIONS}

This study compared performances of alternative ML techniques to classify compensations in construction disputes. Experiments showed that the best performance was obtained from the NB OvA classifier with $80.61 \%$ average classification accuracy. The outcomes of this research are expected to contribute to avoidance or mitigation of disputes. The proposed conceptual model can be an effective guide as it highlights the influential factors related to compensations. Moreover, the promising results from the ML-based classification model show that it is possible to forecast compensations in disputes, which can help to avoid inconclusive processes as parties have better understanding of claims during decision-making. The next step aims to quantify the identified compensations within acceptable precision. Moreover, the extent of experimented ML techniques was limited. Considerable classification techniques (i.e., deep learning techniques) that were not evaluated will be considered as further research.

\section{REFERENCES}

Arditi, D. \& Pulket, T. 2005. Predicting the outcome of construction litigation using boosted decision trees. Journal of Computing in Civil Engineering, 19 (4), pp. 387-393.

Arditi, D. \& Pulket, T. 2010. Predicting the outcome of construction litigation using an integrated artificial intelligence model. Journal of Computing in Civil Engineering, 24 (1), pp. 73-80. DOI: 10.1061/(ASCE)08873801(2010)24:1(73).

Awwad, R., Barakat, B. \& Menassa, C. 2016. Understanding dispute resolution in the Middle East region from perspectives of different stakeholders. Journal of Management in Engineering, 32 (6), art. no. 05016019. DOI: 10.1061/(ASCE)ME.1943-5479.0000465.

Ayhan, M. 2019. Development of dispute prediction and resolution method selection models for construction disputes. Ph. D. thesis Middle East Technical University, Ankara, Turkey. 
Chau, K.W. 2007. Application of PSO-based neural network in analysis of outcomes of construction claims. Automation in Construction, 16 (5), pp. 642-646. DOI: 10.1016/j.autcon.2006.11.008.

Chen, J.H. \& Hsu, S.C. 2007. Hybrid ANN-CBR model for disputed change orders in construction projects. Automation in Construction, 18 (5), pp. 597-604. DOI: 10.1016/j.autcon.2007.03.003.

Cheung, S.O., Au-Yeung R.F. \& Wong, V.W.K. 2004. A CBR based dispute resolution process selection system. International Journal of IT in Architecture, Engineering and Construction, 2 (2), pp. 129-146.

Chou, J.S. 2012. Comparison of multilabel classification models to forecast project dispute resolutions. Expert Systems with Applications, 39 (12), pp. 10202-10211. DOI: 10.1016/j.eswa.2012.02.103.

Chou, J.S. Cheng, M.Y. \& Wu, Y.W. 2013. Improving classification accuracy of project dispute resolution using hybrid artificial and support vector machine models. Expert Systems with Applications, 40 (6), pp. 2263-2274. DOI: 10.1016/j.eswa.2012.10.036.

Chou, J.S., Cheng, M.Y., Wu, Y.W. \& Pham, A.D. 2014. Optimizing parameters of support vector machine using fast messy genetic algorithm for dispute classification. Expert Systems with Applications, 41 (8), pp. 39553964. DOI: 10.1016/j.eswa.2013.12.035.

Chou, J.S., Hsu, S.C., Lin, C.W. \& Chang, Y.C. 2016. Classifying influential information to discover rule sets for project disputes and possible resolutions. International Journal of Project Management, 34 (8), pp. 1706-1716. DOI: 10.1016/j.ijproman.2016.10.001.

Fenn, P. 2007. Predicting construction disputes: an aetiological approach. Management, Procurement and Law, 160 (2), pp. 69-73. DOI: 10.1680/mpal.2007.160.2.69.

Frank, E., Mark, H.A. \& Witten, I.H. 2016. The WEKA Workbench. Online appendix for data mining: practical machine learning tools and techniques. Morgan Kaufmann, Burlington.

Ilter, D. 2010. Opinions of legal professionals regarding the selection of appropriate resolution method in construction disputes. Proceedings of RICS COBRA Annual Construction, Building, and Real Estate Research Conference. Paris, France. DOI: 10.1108/ijdrbe.2010.43501aab.001.

Kisi, K.P., Lee, N., Kayastha, R. \& Kovel, J. 2020. Alternative dispute resolution practices in international road construction projects. Journal of Legal Affairs and Dispute Resolution in Engineering and Construction, 12 (2). DOI: 10.1061/(ASCE)LA.1943-4170.0000373.

McHugh, M.L. 2013. The chi-square test of independence. Biochemica Medica, 23 (2), pp. 143-149. DOI: 10.11613/BM.2013.018.

Nasirzadeh, F., Carmichael, D.G., Jarban, M.J. \& Rostamnezhad, M. 2019. Hybrid fuzzy-system dynamics approach for quantification of the impacts of construction claims. Engineering, Construction \& Architectural Management, 26 (7), pp. 1261-1276. DOI: 10.1108/ECAM-08-2017-0150.

Ren, Z., Anumba, G.J. \& Ugwu, O.O. 2001. Construction claims management: towards an agent-based approach. Engineering, Construction \& Architectural Management, 8 (3), pp. 185-197. DOI: 10.1108/eb021181.

Sharifi, M.M. \& Bagherpour, M. 2016. Optimizing cash-flow-at-risk in construction projects: a cost reduction approach. Periodica Polytechnica Civil Engineering, 60 (3), pp. 337-344. DOI: 10.3311/PPci.7884.

Siam, A., Ezzeldin, M. \& El-Dakhakhni, W. 2019. Machine learning algorithms for structural performance classifications and predictions: application to reinforced masonry shear walls. Structures, 22, pp. 252-265. DOI: 10.1016/j.istruc.2019.06.017.

Weisburd, D. \& Britt, C. 2007. Chapter 13: Measures of association for nominal and ordinal variables. In: Statistics in Criminal Justice. pp. 335-380. Springer, Boston.

Witten, I.H., Frank, E., Hall, M.A. \& Pal, C.J. 2017. Data mining: practical machine learning tools and 